\title{
GRUPO DE ESTUDOS EM FORMAÇÃO DE PROFESSORES E INTERDISCIPLINARIDADE: CONCEPÇÕES, POLÍTICAS E PRÁTICAS DE FORMAÇÃO DE PROFESSORES
}

\author{
Andréa Kochhann ${ }^{1}$ \\ Alice Carlos Feliciano ${ }^{2}$ \\ Douglas Correia dos Santos ${ }^{3}$ \\ Natália Ribeiro Teixeira ${ }^{4}$ \\ Patrícia Ramiro ${ }^{5}$ \\ Vanessa Amélia da Silva Rocha ${ }^{6}$
}

\section{INTRODUÇÃO}

Para Demo (2006) a pesquisa é a base do ensino e extensão. Para a Universidade Estadual de Goiás - UEG essa tríade é elemento fundante da política educacional. Assim, em 2006, criou-se o GEFOPI - Grupo de Estudos em Formação de Professores e Interdisciplinaridade. O foco do grupo é o ensino, a pesquisa e a extensão, como atividade complementar dos acadêmicos da UEG.

Enquanto ensino, estudam com palestras ou pequenos grupos. Como pesquisa, efetivam projetos de investigação científica. Transformam esses resultados em projetos de extensão, iniciação a docência, monografias de graduação ou pós-graduação. Também participam de eventos científicos, obtendo publicações. Objetivos do GEFOPI: discutir sobre formação de professores e interdisciplinaridade, aprofundar nas técnicas de escrita e

\footnotetext{
${ }^{1}$ Docente efetiva da Universidade Estadual de Goiás - Brasil e doutoranda em educação pela Universidade de Brasília andreakochhann@yahoo.com.br

${ }^{2}$ Acadêmica do curso de Matemática da Universidade Estadual de Goiás Câmpus Jussara Brasil. alicecarlosfeliciano@gmail.com

${ }^{3}$ Pedagogo pela Universidade Estadual de Goiás Câmpus São Luis de Montes Belos e pósgraduando em Docência Universitária pelo Câmpus Sanclerlândia - Brasil douglascorreiadossantos@gmail.com

${ }^{4}$ Acadêmica do curso de Pedagogia da Universidade Estadual de Goiás Câmpus São Luis de Montes Belos - Brasil nataliaribeiro7@hotmail.com

${ }^{5}$ Acadêmica do curso de Matemática da Universidade Estadual de Goiás Câmpus Jussara Brasil patriciaramirocarlos@gmail.com

${ }^{6}$ Acadêmica do curso de Matemática da Universidade Estadual de Goiás Câmpus Jussara Brasil vanessa-amelia-silva@hotmail.com
} 
apresentação científica, publicar, preparar para pós-graduação e docência superior.

\section{METODOLOGIA}

Atualmente, o GEFOPI, está no Câmpus São Luis de Montes Belos e Câmpus Jussara. O GEFOPI é um grupo composto por professores, acadêmicos, egressos e interessados, que se reúnem a cada quinze dias, para discutirem temas relacionados à formação de professores. A partir dessas reuniões quinzenais são organizadas as reuniões semanais e as discussões em grupos menores ou individual. Alguns componentes do grupo participam somente das reuniões quinzenais. Outros, com base nas discussões do grupo, organizam projetos de pesquisa, dede extensão e iniciação a docência.

As atividades do GEFOPI são dinâmicas e o envolvimento com eventos científicos têm crescido. As discussões do grupo também acontecem virtualmente. O GEFOPI tem dois grupos no WhatzApp. Um dos grupos chama "GEFOPI" pelo qual agendamos as atividades, conversamos questões cotidianas que envolvem os componentes. O outro grupo é o "GEFOPI em Ação" pelo qual discutimos teoria. Existem temporariamente, grupos do GEFOPI que são criados para a organização de determinado evento.

Os grupos pelo WhatzApp favorecerem muito as atividades do GEFOPI e o desenvolvimento dos acadêmicos, porque a maioria reside em cidades diferentes. Por isso os encontros presenciais são quinzenais e os semanais são agendados conforme a disponibilidade dos acadêmicos de estarem na instituição no período diurno. Os estudos são com base nas temáticas dos projetos de pesquisa e de extensão ou do interesse dos componentes do grupo. Os componentes têm uniforme e vários banners, que utilizam nas apresentações, divulgando a marca do GEFOPI e almejando reconhecimento do grupo academicamente.

\section{RESULTADOS E DISCUSSÃO}

Entre 2013 e 2015, o GEFOPI realizou vários encontros gerais e os encontros semanais foram intensos. Os encontros gerais discutiram sobre a 
aprendizagem significativa, a identidade do pedagogo escolar e não escolar, o uso de filmes em sala de aula, relação coaching na educação, a interdisciplinaridade, análise dos filmes "O óleo de Lorenzo", "A escola da vida", "O espelho tem duas faces", a formação de professores de ciências, a extensão universitária e a formação acadêmica, entre outros temas.

As discussões semanais visavam o planejamento e estudos sobre os projetos de pesquisa e de extensão, bem como as elaborações das monografias e textos para participação em eventos científicos. Os projetos de extensão realizados foram "Cinema e Educação: uma experiência crítica em sala de aula", "Compreendendo a aprendizagem significativa na perspectiva de David Ausubel", "Conhecendo a identidade do pedagogo: professor, gestor e pesquisador" e "Revista Pedagógica: uma análise sociológica em educação".

Os projetos de pesquisas foram "As contribuições de Paulo Freire nas dimensões do ensino, pesquisa e extensão", "O desenvolvimento curricular na escola municipal Gente Miúda: um estudo de caso", "A filosofia e a aprendizagem significativa como contribuição para a construção da autonomia", "O estilo de aprendizagem e a aprendizagem significativa: uma experiência no ensino superior". Os teóricos discutidos nos encontros são os que embasam as temáticas dos projetos e vice-versa. Os relatórios das atividades, os textos produzidos e os slides das atividades são disponibilizadas no slideshare. $O$ GEFOPI tem mais de setenta publicações no slideshare e dez moviemaker no youtube. As fotos das atividades estão postadas no facebook "GEFOPI Andréa".

Os componentes participam e organizam eventos científicos, apresentando banners, mesas redondas, palestras, minicursos e comunicações. Essas participações rendem-Ihes publicações em anais de eventos. Alguns eventos que organizam são reflexos das pesquisas e do ensino, constituindo-se em extensão. Outros são eventos regionais, nacionais ou internacionais. Em algumas cidades, o grupo participa ou realiza mais de um evento e com públicos variados.

Por exemplo, nos dois últimos anos, em São Luis de Montes Belos foram mais de 10 eventos, Jussara e Goiânia 4 eventos, Anápolis 3 eventos, Pires do Rio, Sanclerlândia, Caldas Novas e Mineiros 2 eventos, Goianésia, Formosa, Paraúna, Luziânia, Morrinhos, Porangatu, Itapuranga, Goiás e 
Firminópolis 1 evento. Também participamos em Dourados - Mato Grosso, Belém - Pará e Rosário - Argentina. Lançamos o livro: "Aprendizagem significativa na perspectiva de David Ausubel". Outro em revisão: "Cinema e Educação: uma experiência crítica em sala de aula". Outros três em gestação, provisoriamente intitulados: "A identidade do pedagogo em discussão", "Aprendizagem significativa: múltiplas visões" e "GEFOPI: dez anos de atividades".

Nas avaliações que foram realizadas com os acadêmicos que participam das atividades do GEFOPI, é possível afirmar que o processo de indissociabilidade foi efetivado, que a produção científica e a prática pedagógica foram compreendidas e praticadas. A comunidade externa que recebeu as palestras, minicursos, mesas redondas, afirma em seus questionários que as atividades do grupo são ótimas e propicia a transformação dos pensamentos e produções. As universidades têm como principio a pesquisa, ensino e extensão.

Além disso, a importância da pesquisa passa pela a lapidação do pesquisador e, isto não é mero ao acaso, pois são as experiências que possibilitam um processo de amadurecimento do pesquisador. Neste ínterim segundo Goldenberg (2004, v p.68) "o verdadeiro pesquisador busca é o jogo criativo de aprender como pensar e olhar cientificamente". E o GEFOPI, busca integrar esses princípios de ensinar os acadêmicos a aprender a pensar mediante as problemáticas levantadas na formação de professores.

Assim, ainda conforme Goldenberg (2004, p.69) a arte da pesquisa, o pesquisador segue determinados princípios, sejam eles pessoais ou não, estes princípios são: "ética, curiosidade, interesse real, empatia, paciência, paixão, equilíbrio, humildade, flexibilidade, iniciativa, disciplina, clareza, objetividade, criatividade, concentração, delicadeza". A qualidade do pesquisador exige características tanto intrínsecas quanto extrínsecos, isto é, ele faz parte do meio, e com isso relaciona-se diretamente com o objeto de estudo.

A principio, estabelecer conectividade entre a universidade e a sociedade é, manter elos imbricados, são recíprocos, pois qualquer produção no campo intelectual, de certa forma, mantém vínculos com efetivos na sociedade (seja ela civil ou cientifica). O papel da universidade e as pesquisas 
se fazem cada vez mais necessários, pois os detrimentos que há na formação de professores. Deste modo, Gramsci (2015, p. 3) diz que:

Qualquer grupo social que surge como base original de uma função essencial no mundo da produção econômica, estabelece junto dele, organicamente, um ou mais tipos de intelectuais que lhe dão homogeneidade não apenas no aspecto econômico, mas também no aspecto social e político.

A viabilidade da pesquisa no escopo social tem a nomenclatura de sanar alguns déficits derivado do sistema econômico. Neste sentido, destacase a desigualdades, nos quais na universidade, se distinguindo as formas que os indivíduos colocam em xeque seus objetivos. $O$ trabalho intelectual exige esforço, apesar de ser, um trabalho imaterial, este por sua fez demanda dedicação por parte do pesquisador. Sendo, a universidade "o instrumento de preparação intelectual de diversas categorias" Gramsci (2015, p. 8).

Para 2016 o grupo está com dois projetos de extensão em andamento e um projeto de pesquisa contendo cinco subprojetos, tendo acadêmicos da graduação em Pedagogia e Matemática; e de pós-graduação envolvidos. Uma das pesquisas tem como objetivo analisar as contribuições e dificuldades encontradas pelos componentes do grupo desde sua criação em 2006. As entrevistas estão acontecendo e alguns resultados já estão aparecendo.

Já foram realizadas oito entrevistas e um questionário, devido a distância que a pessoa se encontra. Os dados obtidos foram para além de memórias, mas alguns certificados das primeiras atividades realizadas e também algumas fotografias. Cada entrevistado contou sobre as contribuições que o grupo trouxe para seu aprendizado e para sua vida. Também apareceram algumas dificuldades, como principalmente de transporte para a realização das atividades, pois eram muitas e havia apenas um carro da instituição para atender todas as demandas.

A diretora da UEG, na época de sua criação e anterior a essa época, relatou sobre o envolvimento da coordenadora do grupo com questões de pesquisa e de extensão, inclusive como coordenadora de extensão. E que essas atividades lhe instigaram a criar um grupo de estudos. A mesma avalia como importante esse tipo de atividade na academia, pois favorece o 
envolvimento dos acadêmicos com a produção científica e com as ações de pesquisa e extensão.

Sendo assim o GEFOPI possibilita aos acadêmicos um maior entrosamento com as atividades que devem ser realizadas no âmbito universitário que é o ensino, pesquisa e extensão. Infere-se que muitas vezes os encontros e escritas de artigos para participação de eventos faz com que o aluno aprenda mais do que se estivesse dentro de sala de aula.

Os trabalhos acadêmicos influenciam os componentes do grupo a ter o gosto pela leitura e pela pesquisa. Desta forma a inserção dos mesmos em pós-graduações lato sensu e stricto sensu ficará mais acessível.

\section{CONSIDERAÇÕES}

Assim, devem desenvolver atividades para além do ensino, oportunizando a produção do conhecimento, com grupos de estudos, iniciação a docência, projetos de pesquisa e de extensão. Por isso, o GEFOPI foi criado. Consequentemente $\mathrm{o}$ trabalho da indissociabilidade pesquisa, ensino e extensão foi alcançado. Alguns componentes são ouvintes das discussões presenciais ou virtuais, outros vinculados a projetos de pesquisa ou extensão, monitorias, apoio docente, monografias, dissertações, teses e eventos científicos.

O GEFOPI, registrado na PrE e PrG, tem em média 30 componentes permanentes e 32 flutuantes. Já alcançamos transformações. Os componentes do grupo passaram em pós-graduações. A comunidade externa teve a inserção de uma disciplina no curso de Pedagogia e passaram a discutir sobre aprendizagem significativa. Para 2016, os componentes do GEFOPI têm expectativas grandiosas.

\section{REFERÊNCIAS}

DEMO, Pedro. PESQUISA: Princípio científico e educativo. 12 ed. São Paulo: Cortez, 2006.

GRAMSCI, Antonio. A formação dos intelectuais. Rio de Janeiro: Rizoma, 2015. 
GOLDENBERG, Mirian. A arte de pesquisar: Como fazer pesquisa qualitativa em ciências sociais. 8.ed. Rio de Janeiro: Record, 2004.

FONTES FINANCIADORAS - Universidade Estadual de Goiás com bolsa Monitoria, bolsa Pro-licenciatura, bolsa Permanência, bolsa PIBID, bolsa Extensão, bolsa PIBIC, bolsa FAPEG, bolsa CNPQ, GEPFAPE e apoio financeiro a eventos. 